Revised manuscript for International Journal of Green Energy, September 2009

\title{
SURFACE TEMPERATURE DISTRIBUTION OF CHINESE KANGS
}

Hua Qian ${ }^{1 *}$, Yuguo $\mathrm{Li}^{2}$, Xiaosong Zhang ${ }^{1}$, Jiaping Liu ${ }^{3}$

${ }^{1}$ School of Energy and Environment, Southeast University,

No. 2 Sipailou Road, Nanjing, 210096, China

${ }^{2}$ Department of Mechanical Engineering, University of Hong Kong,

Pokfulam Road,

Hong Kong SAR, China

${ }^{3}$ School of Architecture, Xi'an University of Architecture and Technology, Xi’An 710005, China

\section{Running head: Chinese kangs}

Abstract:

text including references:

*Corresponding Authors

Dr Hua Qian

School of Energy and Environment, Southeast University, No. 2 Sipailou Road, Nanjing, 210096, China

Tel: 86-13645186001

fax:

email: keenwa@gmail.com
222 words

3033 words 


\title{
Revised manuscript for International Journal of Green Energy, September 2009
}

\section{SURFACE TEMPERATURE DISTRIBUTION OF CHINESE KANGS}

\author{
Hua Qian ${ }^{1 *}$, Yuguo $\mathrm{Li}^{2}$, Xiaosong Zhang ${ }^{1}$, Jiaping $\mathrm{Liu}^{3}$ \\ ${ }^{1}$ School of Energy and Environment, Southeast University, \\ No. 2 Sipailou Road, Nanjing, 210096, China \\ ${ }^{2}$ Department of Mechanical Engineering, University of Hong Kong, \\ Pokfulam Road, Hong Kong SAR, China \\ ${ }^{3}$ School of Architecture, Xi'an University of Architecture and Technology, Xi'An 710005, China \\ *Email: keenwa@gmail.com
}

\begin{abstract}
This study is attempted to improve local thermal comfort of Chinese kang through improving the uniformity of the faceplate temperature distribution using CFD simulations. The faceplate temperature of kangs is determined by the heat input to the kangs, the smoke flows and the kang body materials. The smoke flow rate and the kang body temperature are coupled. The distribution of the faceplate temperature is determined by the interior structure and smoke flow path design. In addition to a recent experimental study using infrared thermal imaging, this study uses computational fluid dynamics simulations to analyze in detail the heat transfer and smoke flow processes in a typical Chinese kang. Different design methods for improving temperature distribution of the kang faceplate are compared. Our results show that the temperature distribution on the faceplate of kang can be made to be more even using simple variations in its design.
\end{abstract}

KEYWORDS: Chinese kang, Home Heating, Building Energy, Temperature distribution, CFD

\section{INTRODUCTION}

Chinese kang is an ancient heating system that integrates cooking, sleeping, heating and ventilation, which has been used in northern China for more than 2000 years. Chinese kang embodies traditional northern Chinese culture and lifestyle. It is still widely used today by an estimated 175 million people and 45 million rural families; see a recent review of Zhuang et al. (2009a). 
A typical Chinese kang has a stove, a kang body (including a sleeping platform made of bricks or other forms of fired clay, and an interior cavity), and a chimney. The hot flue gas from cooking fire is led to interior cavity of the kang body by thermal buoyancy, and exhausted through the chimney; see Figure 1. The heat is convected and radiated from the kang surface into the room for home heating. The warm kang itself is also used for sleeping based on the local thermal comfort principle. A kang can heat the bedroom for the whole night by cooking once or twice in the evening due to the thermal storage of the kang body.

The Chinese kang has been recently caught the attention of the scientific community in China. A kang is usually worked together with a stove, and a traditional stove mostly burns biomass such as straw and stalk, or dry wood etc. As living standard improves, there is a trend that farmers start to replace kangs by modern beds and modern home heating techniques such as radiator using a small coal-fired stove. It has been estimated if the Chinese kangs are completely removed, at least additional 200 million tons of standard coal equivalent will be needed in China, which is about $10 \%$ of the total coal consumption in 2006 in China ( $\mathrm{Li}$ et al. 2009). Due to the potential significant increase of energy consumption in home heating when the 45 million rural homes abandon their traditional kangs, the transition of the Chinese kangs in the near future has been suggested to be the bottle neck of the building energy efficiency in China (Li et al. 2009). On the other hand, each stove in each Chinese kang can be considered a small furnace burning different biomass. The low efficiency of these stoves also means a high production of airborne pollutants, and the indoor air environment in these rural homes has also been a concern.

Zhuang et al. (2009b) presented a macroscopic analysis of the thermal storage and smoke flow in Chinese kangs. The faceplate temperature of kangs is determined by the heat input to the kangs, the smoke flows, the kang body materials etc. The smoke temperature in the kang body and in the chimney is a function of the smoke flow rate through the kang system, while the smoke flow is driven partly by the thermal buoyancy pressure which is determined by the temperature difference between the chimney smoke temperature and ambient air temperature. Hence the smoke flow rate and the kang body temperature are coupled.

One of the most important design parameters is the faceplate temperature of kangs. The faceplate temperature of Chinese kangs is an important parameter for both overall thermal comfort in the 
bedroom, and local thermal comfort during sleeping. One of the significant issues for comfort is the uniformity of the temperature distribution of the faceplate. According to the field measurement data in literature (Yang et al. 1963), the temperature difference (maximum temperature- minimum temperature) for the faceplate of traditional kang can be about $12^{\circ} \mathrm{C}$ to $16^{\circ} \mathrm{C}$. Similar results were also observed by Chen et al. (2007). The temperature difference between kang head end (close to smoke inlet) and kang tail end (smoke outlet) is as high as $33^{\circ} \mathrm{C}$ during firing period for cooking. In a recent more accurate measurement (Zhuang et al. 2008), the temperature difference (maximum temperature- minimum temperature) for the faceplate of an elevated kang can be as high as $60{ }^{\circ} \mathrm{C}$, although the surface temperature seems to be reasonably uniform at the center part of the upper plate. The area close to the kang head end is high with the maximum up to $70^{\circ} \mathrm{C}$, and that close to the kang tail end is low, less than $10^{\circ} \mathrm{C}$. Figure 2 shows the picture of a Chinese kang taken by infra camera, appearing the uneven temperature distribution on kang faceplate. This is not ideal for the thermal comfort of the occupants. The faceplate temperature at these areas needs further improvement. There is a lack of systematic study on improving uniformity of temperature distribution on the faceplate of Chinese kangs. Some literature studies proposed different layouts of flue, which influence the temperature distribution on the surface of faceplate, but no detailed study was available (Zhuang et al. 2009a).

The purpose of this paper is to discuss the methods for improving the temperature uniformity of the kang surface temperature and hence to improve thermal comfort conditions for occupants.

\section{PROCEDURES AND METHODS}

\subsection{Heat transfer process of the kang}

Figure 3 shows a simplified model to illustrate heat transfer process of a kang. Four nodes (1-4) along the smoke flow direction are shown. In Figure 3(A), F is the smoke node in the kang flue and $B$ is the bedroom air node. The kang faceplate node is shown as $P$. The upper surface of the kang body is shown as $\mathrm{U}$, while the lower surface as $\mathrm{D}$. The heat transfer to the walls and the ground is not shown. In Figure 3(B), $R$ is the thermal resistance, $T$ is the temperature and the subscript is the location code shown in Figure 3 (A). 
The residual heat from the stove during cooking enters the flue, heating up the bottom and upper plates. The smoke then enters the chimney being exhausted to the ambient. Such a flow is mainly driven by the thermal stack effect. Hence the chimney design is also important to ensure an upward smoke flow. The warm smoke distributes in the kang body. Without a proper design, it is more likely to have a hot area close to the stove (i.e. the area of $1 \mathrm{U}$, which is commonly refer to as kang head) and relatively not so warm area close to the chimney (i.e. the area of $4 \mathrm{U}$, referred to as kang tail).

A uniform distribution of the faceplate temperature means that the upper surface temperatures $T_{1 \mathrm{U}}, T_{2 \mathrm{U}}, T_{3 \mathrm{U}}, T_{4 \mathrm{U}}$ are sufficiently close. The use of thermal resistance can help us understand the heat transfer process between the flue and the surface of kang. There are a number of methods that can be considered for improving temperature uniformity. However, there have not been any scientific studies about the effectiveness of these methods. Three possible methods can be derived from the illustration in Figure 3(B):

(a) To improve flue (interior cavity) structure of the Chinese kang, which means to make $T_{1 \mathrm{~F}}$, $T_{2 \mathrm{~F}}, T_{3 \mathrm{~F}}, T_{4 \mathrm{~F}}$ to be close. There are a number of possible flue structures to achieve this based on experiences [Zhuang et al, 2009a].

(b) To reduce the thermal resistance $\mathrm{R}_{12 \mathrm{P}}, \mathrm{R}_{23 \mathrm{P}}$ and $\mathrm{R}_{34 \mathrm{P}}$ which can make the temperatures $T_{1 \mathrm{P}}$, $T_{2 \mathrm{P}}, T_{3 \mathrm{P}}, T_{4 \mathrm{P}}$ being close, resulting in the uniform distribution of $T_{1 \mathrm{U}}, T_{2 \mathrm{U}}, T_{3 \mathrm{U}}, T_{4 \mathrm{U}}$.

(c) According to the flue temperature, the thermal resistance $R_{\mathrm{UP}}, R_{\mathrm{DP}}$ can be adjusted. The simplest method is to adjust the thickness of materials according to flue gas temperature.

Figure 3(A) shows what is the normally referred to as grounded kangs. The main characteristics of such grounded kangs are that the volume of the kang body is relatively large. There is a heat transfer from the kang to the ground. If the lower flue boundary is not insulated, there is a heat loss to the ground, which reduces the thermal efficiency of the kang. In the last 30 years, a new elevated kang emerges (Zhuang et al, 2009a). In an elevated kang, the lower flue boundary is lifted up and a new lower kang plate is added. The addition of the lower kang plate adds an additional heat transfer surface from the kang to the bedroom with the additional benefit of avoiding the heat loss from the kang to ground. 


\subsection{Cases for our study}

Following the above mentioned methods, four test cases are studied to investigate the influence of different designs on the temperature distribution on the faceplate:

Case 1. Grid-flue grounded kang, which is widely used; see Figure 4 (A). It is referred to as Case 1 [Grid-flue grounded kang].

Case 2. Elevated kang, which is the latest development of Chinese kang; see Figure 4 (B). It is referred to as Case 2 [Elevated kang].

Case 3. Elevated kang, the same as Case 2 but adding an aluminum board between the flue and faceplate to reduce horizontal thermal resistance; see Figure 4 (C). It is referred to as Case 3 [Elevated kang with an aluminum layer].

Case 4. Elevated kang, the same as Case 2 but the thickness of the plate is different at different locations; see Figure 4 (D). It is referred to as Case 4 [Elevated kang with different plate thickness].

\subsection{Methods}

CFD was used to investigate the smoke flow pattern and heat transfer in demonstration Chinese kangs. The geometry of computational domain was similar to typical Chinese kangs. A commercial CFD package FLUENT including the grid generation software Gambit (Fluent Inc.Lebanon, NH) was used to solve the governing equations for fluid flow.

The turbulence effect is considered by using the Re-Normalization Group (RNG) k- $\varepsilon$ model (Feziger and Peric 2002; Fluent, 2000). The governing equations are given in a vector form as following:

$$
\begin{aligned}
& \frac{\partial \rho}{\partial t}+\operatorname{div}(\vec{V})=0 \\
& \frac{\partial(\rho \phi)}{\partial t}+\operatorname{div}(\rho \vec{V} \phi)=\operatorname{div}\left(\Gamma_{\phi} \operatorname{grad} \phi\right)+S_{\phi}
\end{aligned}
$$


Where $\phi$ is a general scalar quantity, which can represent $u, v, w, k, e$ and $T$. The incompressible ideal gas law was used to calculate the density of air and that of the flue gas. The convection terms of the equations are discretized using the second-order upwind scheme. Only steady state simulation was considered, which means that the first term on the left hand of Equation (1) and Equation (2) is 0.

The heat source for heating Chinese kang in the stove is set to $6 \mathrm{~kW}$ in the stove. We do not model the combustion and heat transfer process in the stove. The stove walls are assumed to be adiabatic so that all the heat input is transported into the kang body. The physical properties of materials used are shown in Table 1. These materials are chosen based on our recent experimental study of a new kang (Zhuang et al. 2009c).

The boundary conditions are shown in Table 2. The outdoor air temperature is $-20^{\circ} \mathrm{C}$ and indoor air temperature is $14.6^{\circ} \mathrm{C}$ and the room surface temperature is also assumed to be uniform at $14.6^{\circ} \mathrm{C}$. The inlet (stove gate) and outlet (chimney) was set as pressure inlet and outlet, and their pressure difference was set as $\rho_{0} g H$, where $\rho_{0}$ is the outdoor air density corresponding to $-20^{\circ} \mathrm{C}$ in this study and $H$ is the height difference of Chimney outlet and stove gate, which is $3.25 \mathrm{~m}$ in this study.

We consider only steady state conditions. The chimney walls are assumed to be adiabatic. For the situation of the grounded kang, the accumulated ashes are considered to have good thermal insulation properties. The lower flue boundary is assumed to be also adiabatic.

\section{RESULTS AND DISCUSSIONS}

\subsection{Heat transfer of the kang faceplate}

The total heat input of kang in different cases was set to be $6 \mathrm{~kW}$. Table 3 summarized mass flow rate, chimney outlet air temperature and heat transfer rate from the kang for different cases. The structure of elevated kang (Case 2) has a higher flow resistance due to the smoke stopper before smoke outlet, hence a lower mass flow rate than the traditional grid-flue grounded kang (Case 1). The results indicating less heat loss through chimney outlet in elevated kang than in traditional grid-flue grounded kang. Only $2.1 \mathrm{~kW}$ was transferred to indoor space in Case 1 [Grid-flue 
grounded kang], while heat transfer rate from the elevated kang in other 3 cases is higher than 3 $\mathrm{kW}$. Compared with the grid-flue grounded kang (Case 1), there is more heat transfer from the elevated kang (Cases 2-4) to indoor space for thermal comfort. It should be noted that the heat loss to ground was ignored in Case 1 [grid-flue grounded kang], which resulted in an overestimation of the heat transfer rate to indoor space. The results indicate that the elevated kang has a higher heat release rate than the grid-flue grounded kang. It is noted that the kang efficiency shown here does not reflect the practical situation, as kang thermal storage is expected to store some heat, which is one of the main characteristics of the kangs.

Case 3 [Elevated kang with an aluminum layer] shows the highest heat release rate which is due to the excellent heat transfer performance of aluminum. Compared with Case 2 [Elevated kang], the lower mass flow rate Case 3 [Elevated kang with an aluminum layer] is due to a lower flue gas and outdoor air temperature difference, which make the pressure difference between stove gate and chimney outlet in Case 3 be lower than that in Case 2. The difference of mass flow rate between Case 2 [Elevated kang] and Case 4 [Elevated kang with different plate thickness] is due to different thickness of the flue. In practice, we need to balance between the heat release rate to the bed room and the amount of heat stored in the kang body.

\subsection{The influence of faceplate temperature distribution by inner structure}

Inner structure influences the smoke flow pattern and its temperature distribution inside flue of kang body, which will influence the temperature distribution of faceplate of kang. A typical gridflue grounded kang has many pillars inside the flue of kang body, which is expected to enhance the smoke flow mixing. A typical elevated kang design removes the pillars replaced by smoke stopper at the tail of kang body, offering less flow resistance in most area flue of kang body. A large recirculation of the smoke flow before smoke stoppers in the kang body is formed, and such recirculation is expected to mix the smoke in the flue of kang body, providing a relatively fully mixed situation.

Figure 5 shows airflow vectors of smoke at the middle plane of the kang body for different cases.

Figure 6 shows the streamline of smoke flow inside the flue. At the middle flue plane, the smoke flow in the elevated kang seems to be more even due to the existence of a large recirculation; see

Figure 5. But the structure of elevated kang does not distribute smoke to the two sides evenly, 
while the grid-flue ground kang (Case 1) seems to make smoke distribute to the two sides of flue more evenly. Figure 7 shows the temperature contour at the middle line of the kang body. The lower smoke temperature in Case 1 is due to a high mass flow rate from inlet.

Figures 8 shows the temperature contours and temperature distribution of the faceplate of kang. The temperature profiles at middle line of the kang and at the line $0.5 \mathrm{~m}, 1 \mathrm{~m}$ and $2 \mathrm{~m}$ away from kang head are shown in Figures 9, 10 and 11 respectively. The simulated kang faceplate temperature profiles shown in Figure 8 and Figure 9 reveal the commonly observed hot-kanghead and cold kang tail phenomenon. The entering hot smoke heats up immediately the kang head area. For the grid-flue grounded kang, the pillars in the kang body enhance the smoke flow mixing but two relatively cold far corner areas at the stove end also exist. For the elevated kang, the large recirculation is insufficient to make smoke fully mixed. Two relatively cold far corner areas at the stove end and kang tail especially behind the smoke stopper can be observed. The results indicate that the improvement of the uniformity of temperature distribution of structure of elevated kang needs further study in spite of that elevated kang has shown a relatively higher heat release rate to indoor space.

Compared with the grid-flue grounded kang (Case 1), the elevated kang (Case 2) does not show more even distribution of the surface plate temperature though its heat release rate to indoor space is higher than the grid-flue grounded kang. The smoke stopper inside the elevated kang doesn't improve the uniformity of faceplate temperature distribution of the kang but improves the heat release rate to indoor space through increasing the flow resistance to the chimney.

\subsection{The influence of plate materials on the surface temperature distribution}

Case 3 [Elevated kang with an aluminum layer] exhibits the best performance in four Cases; see Figure 8(C) and Figure 9-11. In spite of that Case 2 and Case 3 share one inner structure, Case 3 appears to give a better performance than Case 2 . The temperature was ranged from $40^{\circ} \mathrm{C}$ to $50^{\circ} \mathrm{C}$ for Case 3[Elevated kang with aluminum layer] while the temperature was ranged for $30^{\circ} \mathrm{C}$ to $70^{\circ} \mathrm{C}$ for Case 2 [Elevated kang]. Furthermore, Case 3 gives a higher heat release rate to the indoor space, see Table 3. It is due to the good heat transfer performance of the aluminum. Method (b) in Section 2 may be able to explain these phenomena. The results indicate that using a 
good heat conductor at the lower part of the upper plate covered with good heat resistance materials can improve the uniformity of surface temperature distribution. The aluminum as an excellent thermal conductor may be too expensive in practice for constructing a kang, but it may be possible to develop relatively cheap but highly conductive technology or materials for kangs such as using the heat pipe principle. The thermal storage performance of the kangs also needs to be considered. It is important to note that the purpose here is not to enhance the heat release rate from the kang body to the bed room, but to achieve a better uniformity of the faceplate temperature distribution.

Temperature distribution on the faceplate is more even in Case 4 [Elevated kang with different plate thickness] than in Case 2 [Elevated kang], but the improvement was not as obvious as Case 3. The temperature ranged from $30^{\circ} \mathrm{C}$ to $58^{\circ} \mathrm{C}$ in Case 4 while temperature ranged from $30^{\circ} \mathrm{C}$ to $70^{\circ} \mathrm{C}$ for Case 2. This method is very convenient to be used in improving the current design. This is only a very preliminary study. No optimization has been done so far.

\section{CONCLUSIONS}

Based on the analysis of a physical model of Chinese kang, we propose some possible ways to improve the uniformity of the temperature distribution on the faceplate of kang. Four cases were investigated using CFD simulations.

Results show that the new elevated kang gives a higher heat release rate than the traditional gridflue grounded kang. The higher heat release rate for the elevated kang is due to a smaller flue flow rate and an increased heat release area to the indoor air $\mathrm{d}$ due to the additional lower kang plate.

However, the new elevated kang does not show more evenly temperature distribution than the traditional grid-flue grounded kang. The final two cases proposed in this paper appear to provide more even distribution than original elevated kang, especially for Case 3[elevated kang with aluminum]. The maximum temperature difference is less than $10^{\circ} \mathrm{C}$ for Case 3 [elevated kang with aluminum] while it is $28^{\circ} \mathrm{C}$ for Case 4 [Elevated kang with different plate thickness] and 
$40^{\circ} \mathrm{C}$ for Case 2 [Elevated kang]. The present study is very preliminary and only serves as our first attempt and more studies will be carried out.

\section{ACKNOWLEDGEMENT:}

The work described in this paper is supported by the 11th Five Years Support Programs for Science and Technology 2008BAJ12B02 and the National Natural Science Foundation of China (NSFC) 2007 Young Researcher Award (NSFC project number: 50729803).

\section{REFERENCES:}

Chen, B., Z. Zhuang, X. Chen, and X. Jia. 2007. Field survey on indoor thermal environment of rural residences with coupled Chinese kang and passive solar collecting wall heating in Northeast China. Solar Energy 81: 781 - 790.

Fluent. 2001. Fluent 6.0 user's guide. Fluent Inc,.

Feziger, J.H. and M. Peric. 2002. Computational methods for fluid dynamics.3rd ed. Springer, Berlin, 423.

Li, Y., Z. Zhuang, and J. Liu. 2009. Chinese kangs and building energy consumption. Chinese Science Bulletin 54 (6): 992-1002.

Yang, SH. 1963. Study and survey on Chinese kang. Proceeding of Civil and Architectural Institute of North China, China,1963. (in Chinese)

Zhuang, Z., Y. Li, L. Duanmu, B. Chen, H. Qian, S. Wang, Y. Zhao, L. Liu and Y. Sun. 2008. Experimental assessment of thermal performance of an elevated Chinese kang system. First International Conference On Building Energy And Environment 2008, Dalian, July, 2008.

Zhuang Z., Y. Li, and B. Chen . 2009a. Chinese Kang as a Domestic Heating System in Rural Northern China - A Review. Energy and Buildings 41(1): 111-119.

Zhuang Z, Y. Li, and B. Chen . 2009b. Thermal storage performance analysis on Chinese kangs. Energy and Buildings 41(4): 452-459.

Zhuang, Z., Y. Li, L. Duanmu, B. Chen, H. Qian, S. Wang, Y. Zhao, L. Liu and Y. Sun. 2009c. Measured Heat Transfer and Smoke Flow Performance of a Typical Elevated Chinese Kang. Submitted to Energy and Buildings.

\section{List of tables}

Table 1 . The physical property of materials used in simulating the building envelope and the kang body.

Table 2. Boundary conditions of CFD simulation for different cases

Table 3. Heat transfer rate from different surface to indoor space of different cases

\section{List of figures}


Figure 1. (Above) Illustration of a typical Chinese kang; (Below) Photos of a chimney, a kang body (here a corner kang is shown) and a typical large stove in rural northern China.

Figure 2. Picture of kang faceplate taken by infra camera, appearing uneven temperature distribution on the kang faceplate.

Figure 3. Illustration of the relationship of temperature and thermal resistance. (a) the kang structures. (b) the temperature and thermal resistances.

Figure 4. Illustration of four possible kang designs. (A) Case 1 [Grid-flue grounded kang], (B) Case 2 [Elevated kang], (C) Case 3 [Elevated kang with an aluminum layer] and (D) Case 4 [Elevated kang with different plate thickness].

Figure 5. Smoke flow pattern at the middle line of flue of kang body for the four simulated cases.

Figure 6. Streamline of smoke inside flue of kang body from stove gate.

Figure 7. Smoke temperature contour at the middle line of flue of the kang body.

Figure 8. Temperature contours faceplate of kang for different cases. (A) Case 1 [Grid-flue grounded kang]. (B) Case 2 [Elevated kang]. (C) Case 3 [Elevated kang with aluminum layer]. (D) Case 4 [Elevated kang with a different plate thickness].

Figure 9. Temperature profiles along middle line of faceplate of kang for different cases. The position of the middle line was shown in the figure.

Figure 10. Temperature profiles along a horizontal line of faceplate which is $0.5 \mathrm{~m}$ distant from the kang head for different cases. The position of the line was shown in the figure.

Figure 11. Temperature profiles along a horizontal line of faceplate which is $2 \mathrm{~m}$ distant from the kang head for different cases. The position of the line was shown in the figure. 
Table 1 . The physical property of materials used in simulating building envelope and the kang body.

\begin{tabular}{|c|c|c|c|c|c|}
\hline Components & Materials & Thickness (mm) & $\begin{array}{l}\text { Density } \\
\left(\mathrm{kg} / \mathrm{m}^{3}\right)\end{array}$ & $\begin{array}{c}\text { Heat } \\
\text { conductivity } \\
(\mathrm{W} / \mathrm{mK})\end{array}$ & $\begin{array}{c}\text { Specific } \\
\text { heat } \\
(\mathrm{J} / \mathrm{kgK})\end{array}$ \\
\hline Chimney wall & Insulated & - & - & - & - \\
\hline \multirow[t]{2}{*}{ Internal wall } & $\begin{array}{l}\text { Cement } \\
\text { mortar(both sides) }\end{array}$ & 10 & 1800 & 0.930 & 1050 \\
\hline & Brick & 120 & 1668 & 0.430 & 754 \\
\hline Floor & insulated & - & - & - & - \\
\hline \multirow[t]{3}{*}{ Upper plate } & $\begin{array}{l}\text { Aluminum } \\
\text { (optional) }\end{array}$ & $\begin{array}{c}30 \text { (Case 3) } \\
0 \text { (Case 1,2,4) }\end{array}$ & 2719 & 202.4 & 871 \\
\hline & $\begin{array}{l}\text { Asbestine } \\
\text { shingles }\end{array}$ & $\begin{array}{c}30 \text { (Case 1,2) } \\
0 \text { (Case } 3,4)\end{array}$ & 2070 & 0.477 & 1214 \\
\hline & $\begin{array}{l}\text { Cement mortar } \\
\text { (surface of kang) }\end{array}$ & $\begin{array}{c}20 \text { (Case 1,2,3) } \\
\text { Variable (Case 4) }\end{array}$ & 1700 & 0.870 & 1050 \\
\hline Lower plate & $\begin{array}{l}\text { Reinforced } \\
\text { concrete }\end{array}$ & 100 & 2400 & 1.547 & 837 \\
\hline
\end{tabular}


Table 2. Boundary conditions of CFD simulation for different cases

\begin{tabular}{lcc}
\hline Boundary & Type & Value \\
\hline Chimney outlet & Pressure outlet & $-\rho_{0} g H$ Pa, $\rho_{0}=1.34$ corresponding to \\
outdoor air temperature $-20^{\circ} \mathrm{C}$
\end{tabular}


Table 3. Heat transfer rate from different surface to indoor space of different cases

\begin{tabular}{|c|c|c|c|c|c|c|}
\hline \multirow[b]{2}{*}{ Cases } & \multirow{2}{*}{$\begin{array}{l}\text { Mass } \\
\text { flow rate } \\
(\mathrm{kg} / \mathrm{s})\end{array}$} & \multirow{2}{*}{$\begin{array}{c}\text { Outlet } \\
\text { temperature } \\
\left({ }^{\circ} \mathrm{C}\right)\end{array}$} & \multicolumn{4}{|c|}{ Heat transfer rate from different surface (W) } \\
\hline & & & $\begin{array}{l}\text { Upper } \\
\text { plate }\end{array}$ & $\begin{array}{l}\text { Lower } \\
\text { plate }\end{array}$ & $\begin{array}{l}\text { Vertical } \\
\text { wall }\end{array}$ & Total \\
\hline $\begin{array}{l}\text { Case } 1 \text { [grid-flue } \\
\text { grounded kang] }\end{array}$ & 0.0404 & 100.8 & 1625 & - & 489 & 2114 \\
\hline $\begin{array}{l}\text { Case } 2 \text { [Elevated } \\
\text { kang] }\end{array}$ & 0.0319 & 95.1 & 1870 & 1078 & 207 & 3155 \\
\hline $\begin{array}{l}\text { Case } 3 \text { [Elevated } \\
\text { kang with an } \\
\text { aluminum layer] }\end{array}$ & 0.0308 & 84.1 & 2402 & 955 & 183 & 3540 \\
\hline $\begin{array}{lr}\text { Case } 4 & \text { [Elevated } \\
\text { kang } & \text { with } \\
\text { different } & \text { plate } \\
\text { thickness] } & \\
\end{array}$ & 0.0336 & 91.6 & 1935 & 1002 & 210 & 3147 \\
\hline
\end{tabular}



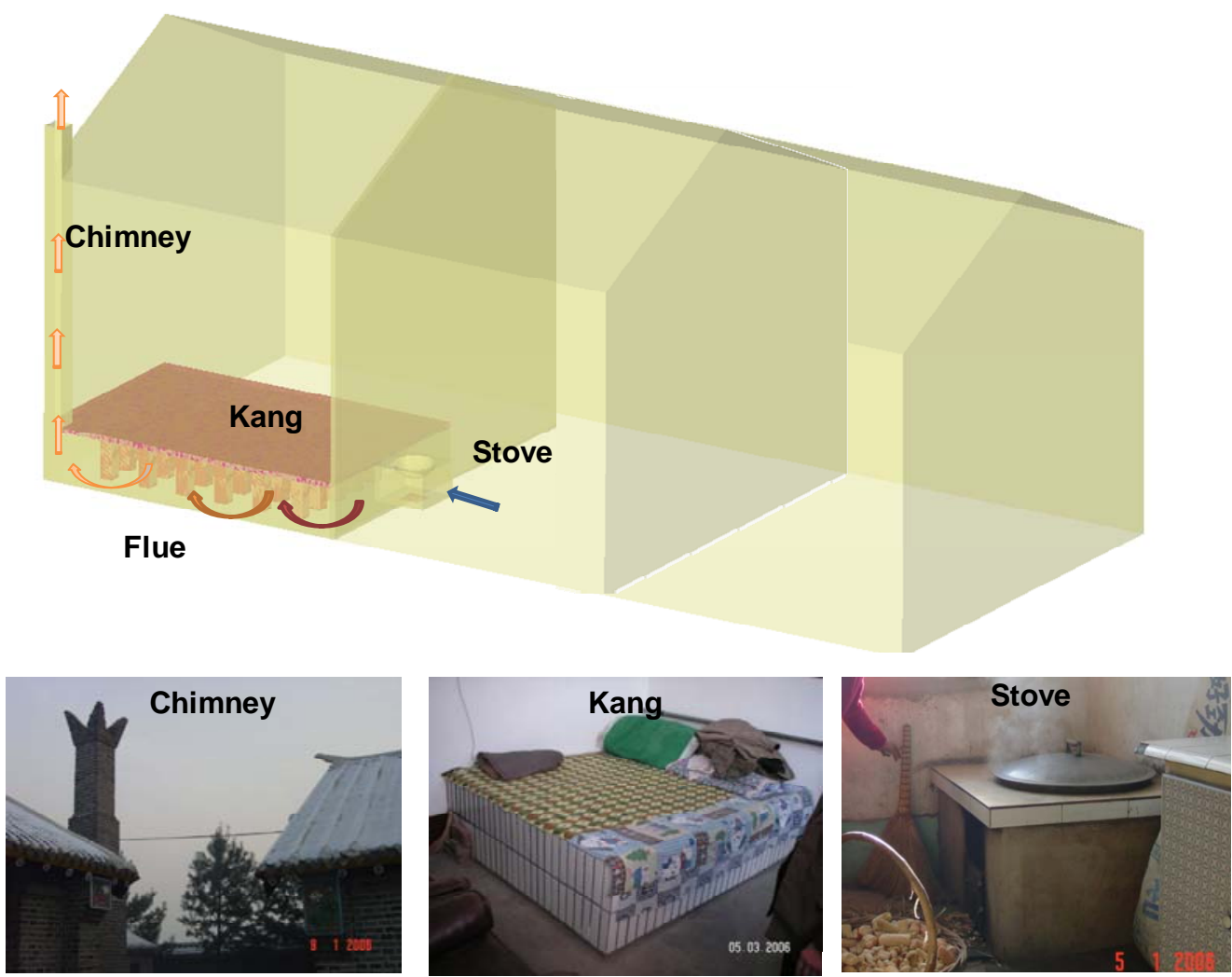

Figure 1. (Above) Illustration of a typical Chinese kang; (Below) Photos of a chimney, a kang body (here a corner kang is shown) and a typical large stove in rural northern China. 


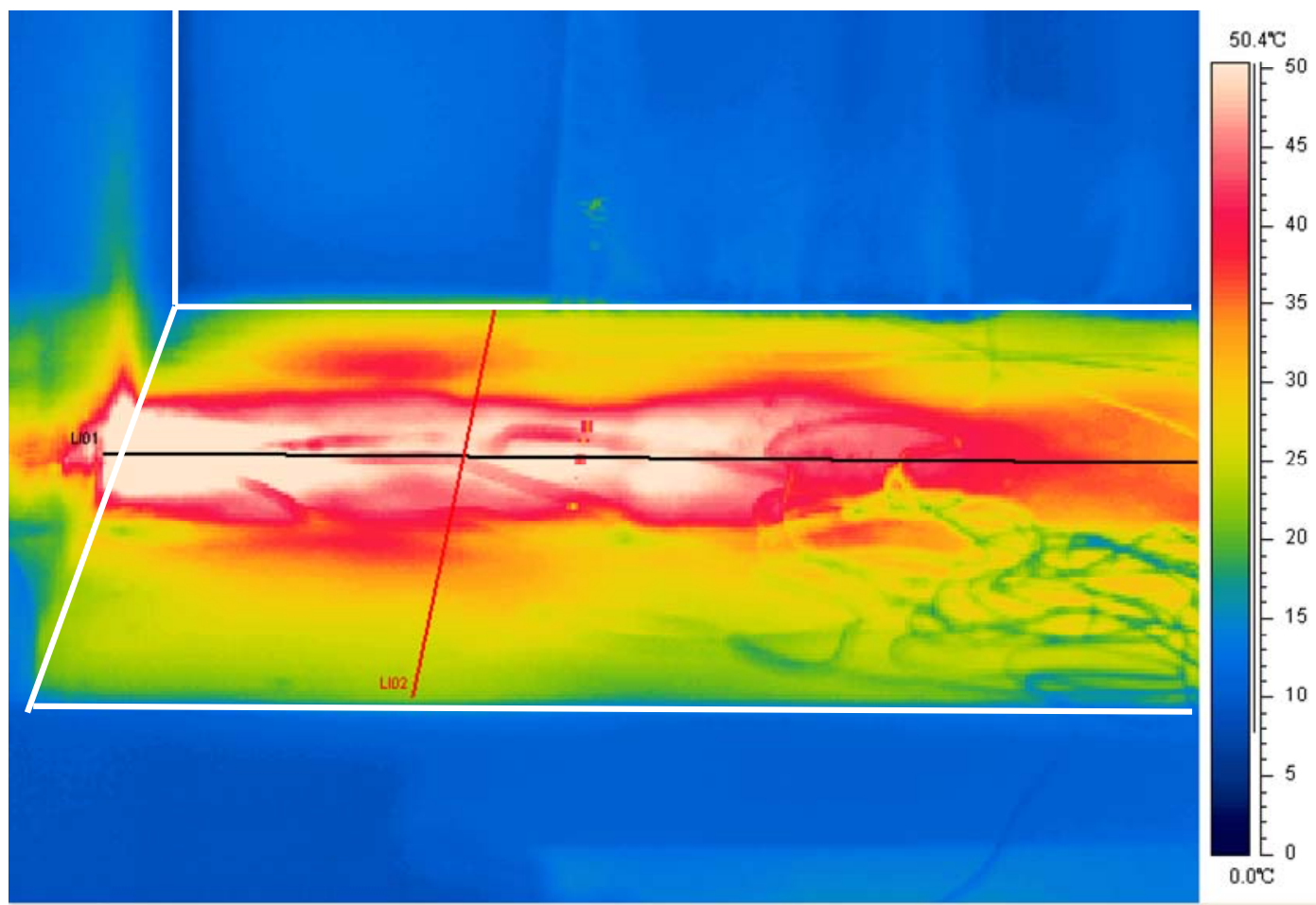

Figure 2. Picture of kang faceplate taken by infra camera, appearing uneven temperature distribution on the kang faceplate 


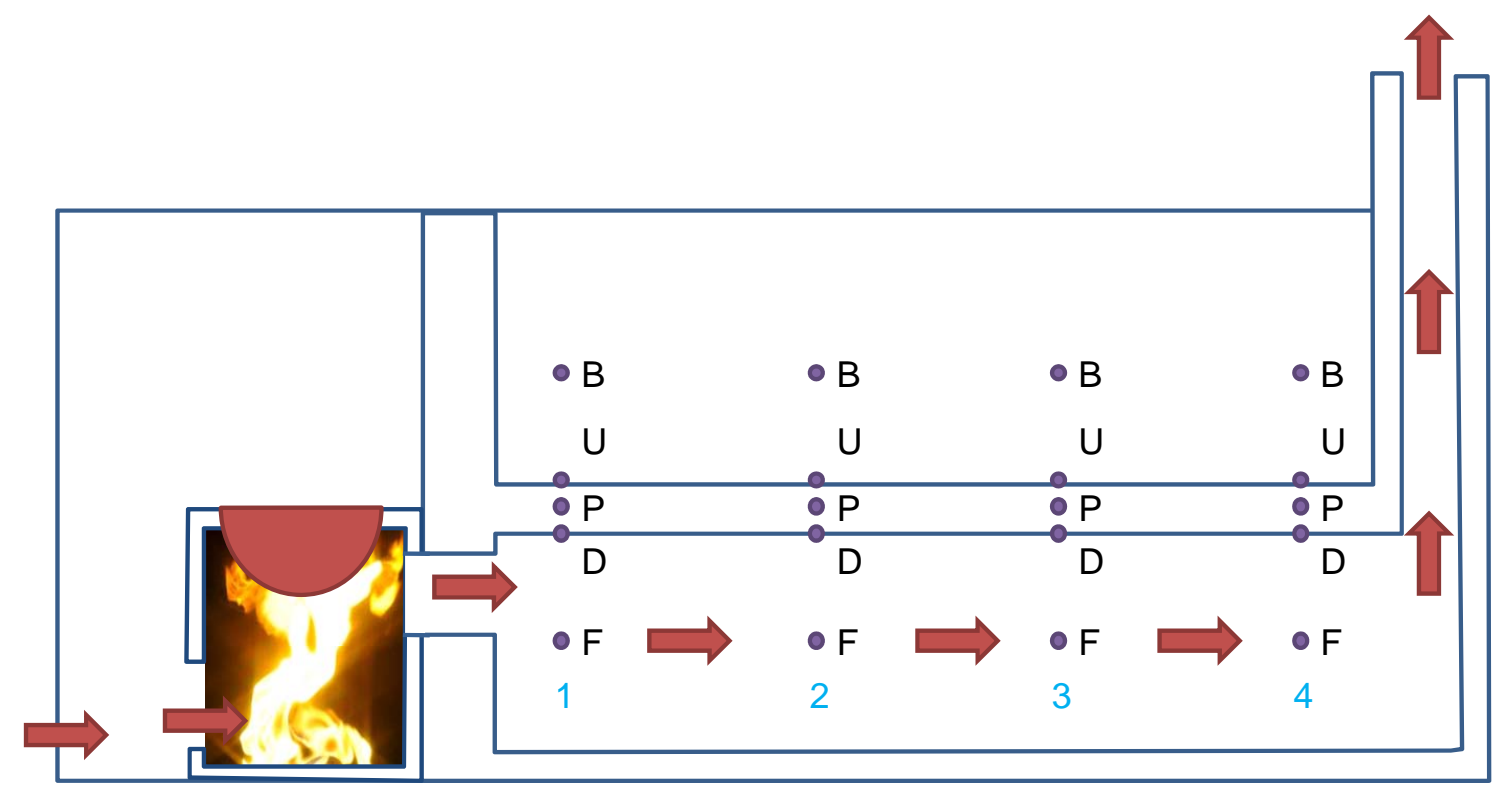

(A)

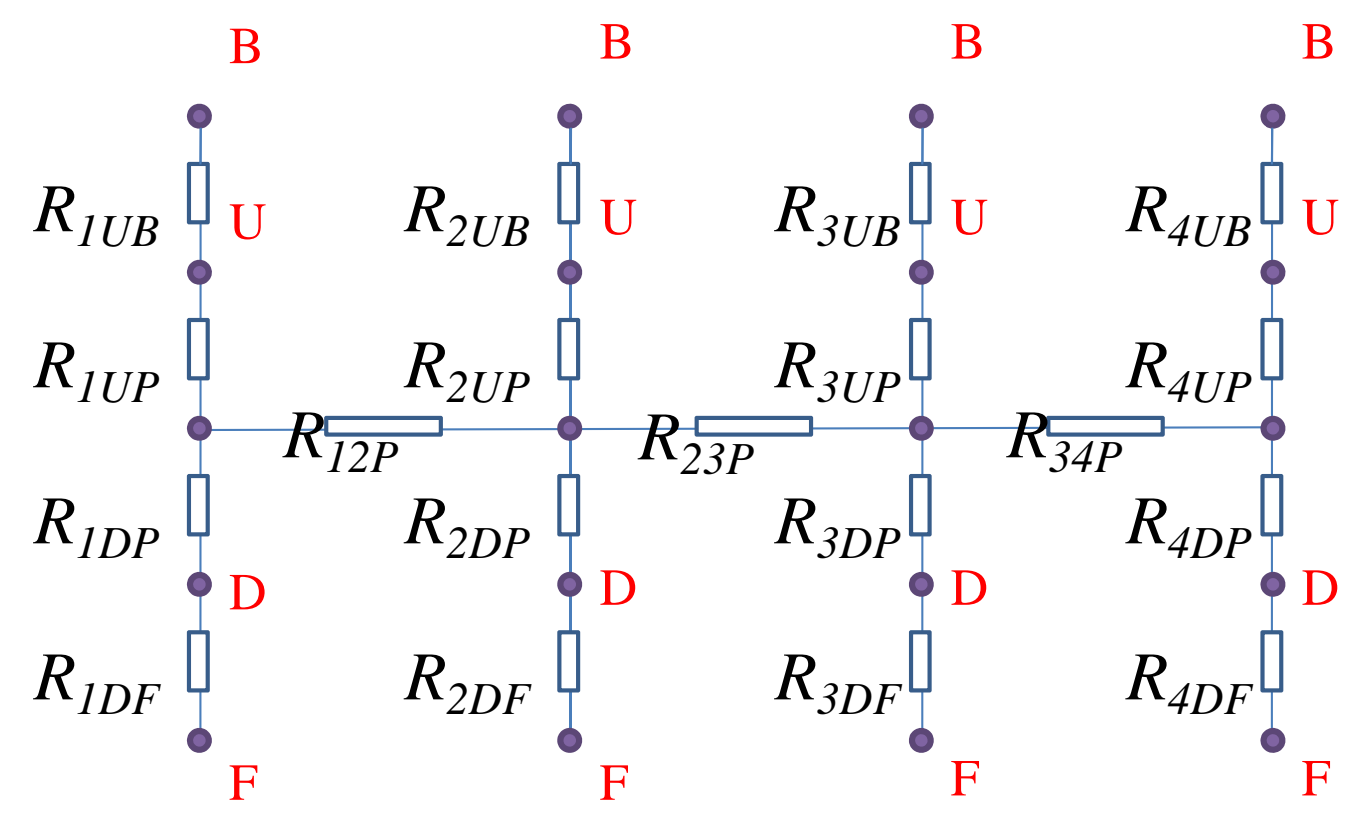

(B)

Figure 3. Illustration of the relationship of temperature and thermal resistance. (a) the kang structures. (b) the temperature and thermal resistances. 


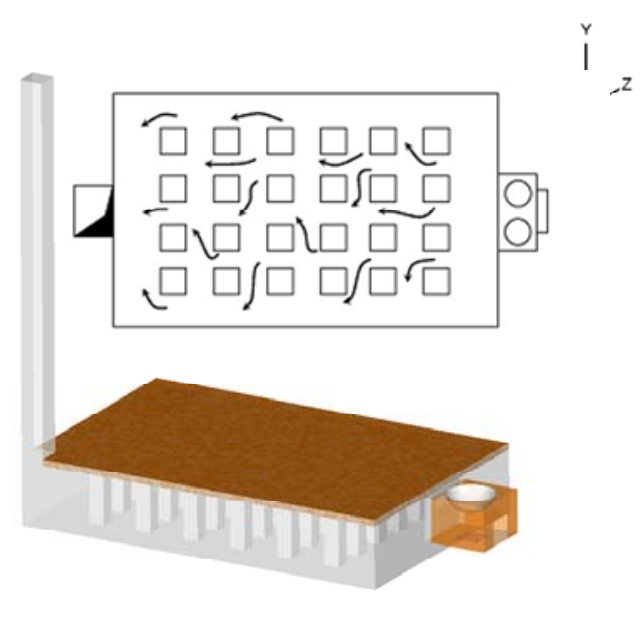

(A)

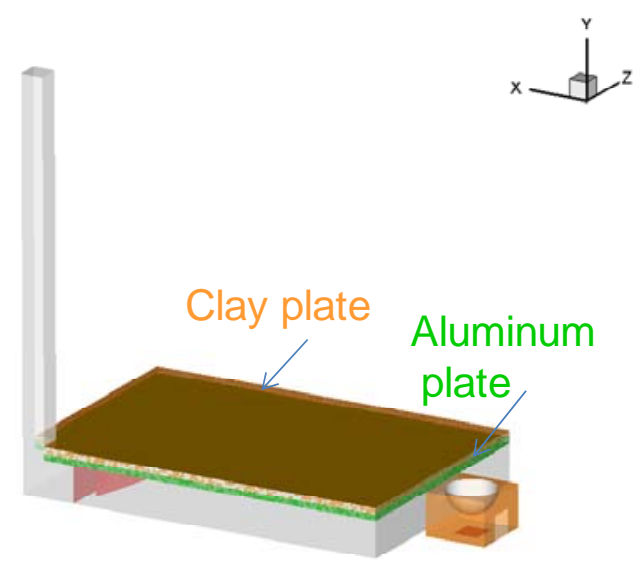

(C)

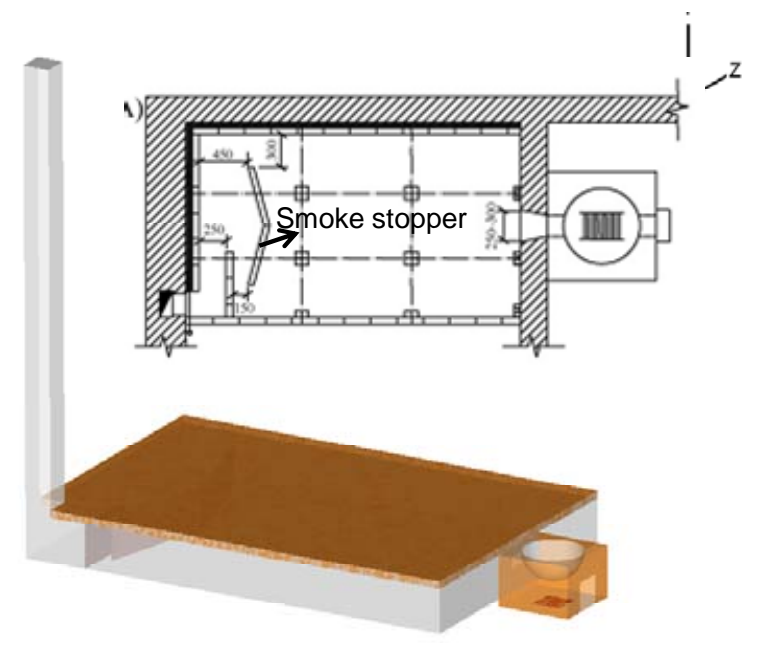

(B)

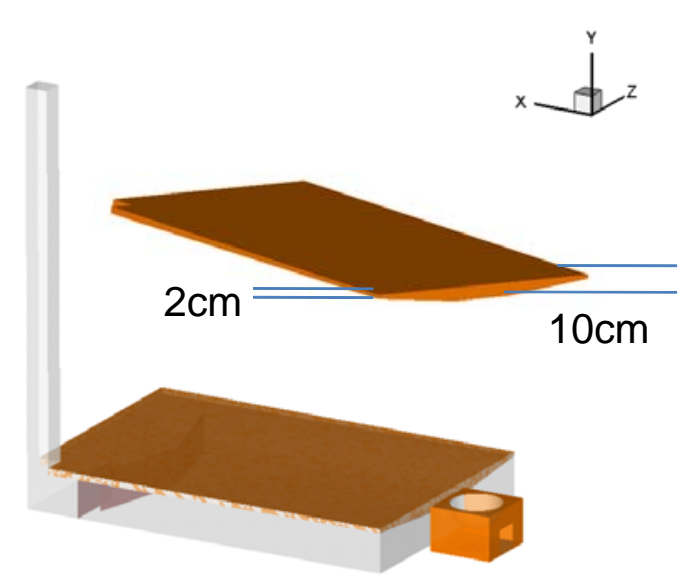

Figure 4. Illustration of four possible kang designs. (A) Case 1 [Grid-flue grounded kang], (B) Case 2 [Elevated kang], (C) Case 3 [Elevated kang with an aluminum layer] and (D) Case 4 [Elevated kang with different plate thickness]. 


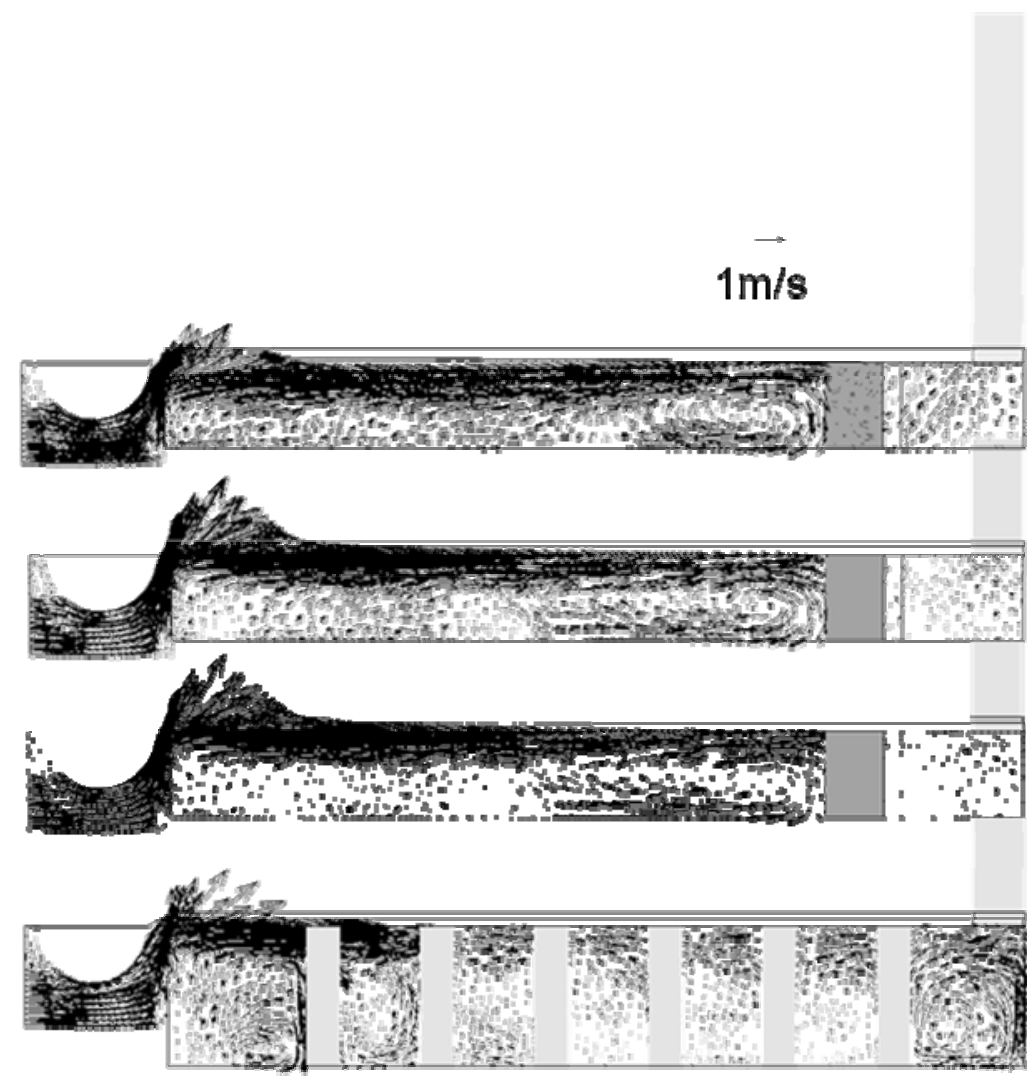

\section{Case 4 [Elevated kangwith different plate thickness]}

\section{Case 3 [Elevated kangwith an aluminum layer]}

\section{Case 2 [Elevated} kang]

\section{Case 1 [Grid-flue grounded kang]}

Figure 5. Smoke flow pattern at the middle plane of the kang flue for 4 simulated cases. 


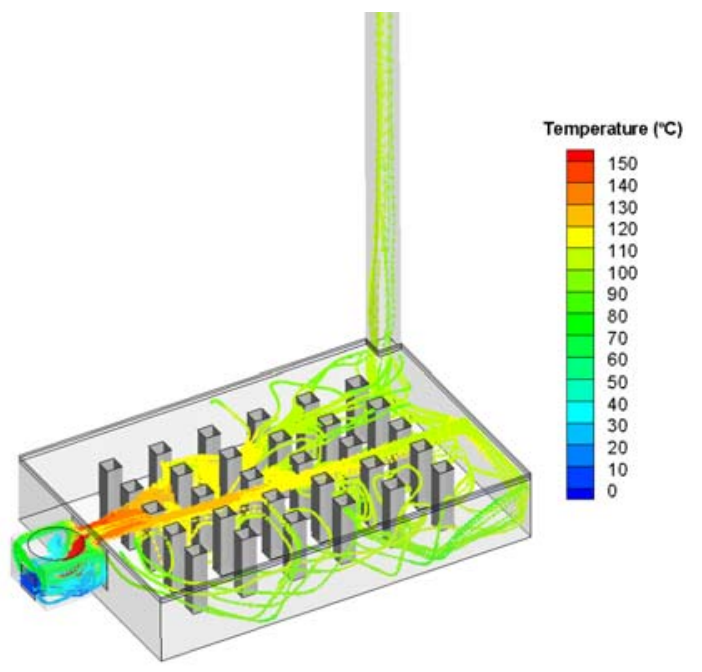

(A)

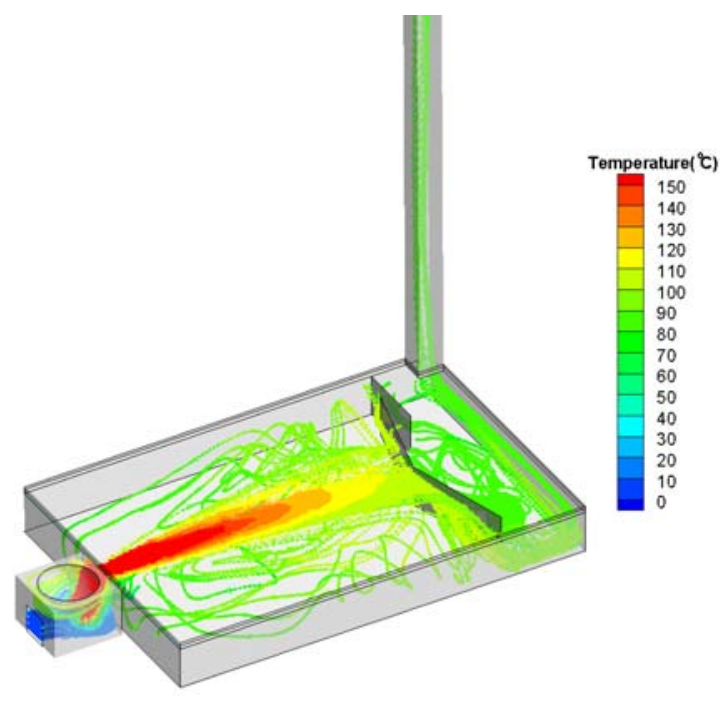

(C)

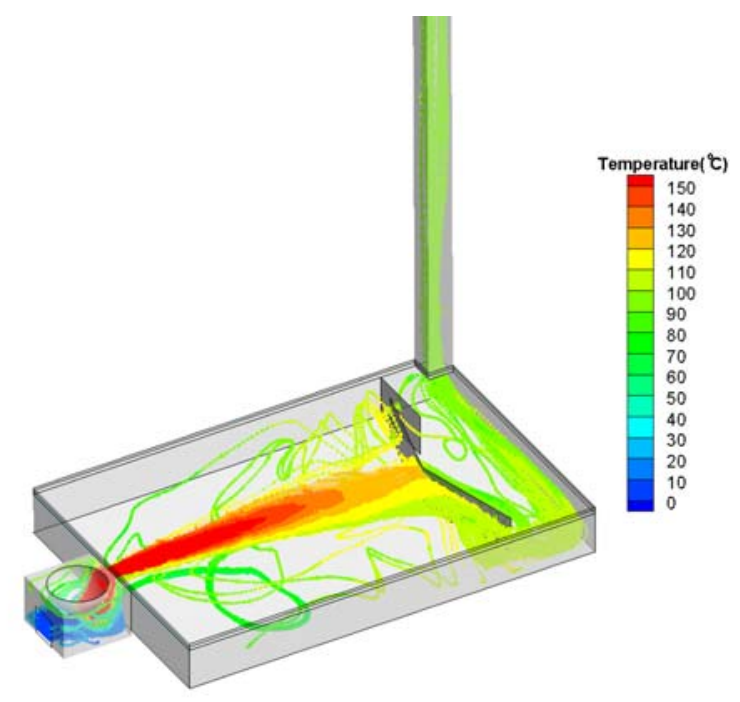

(B)

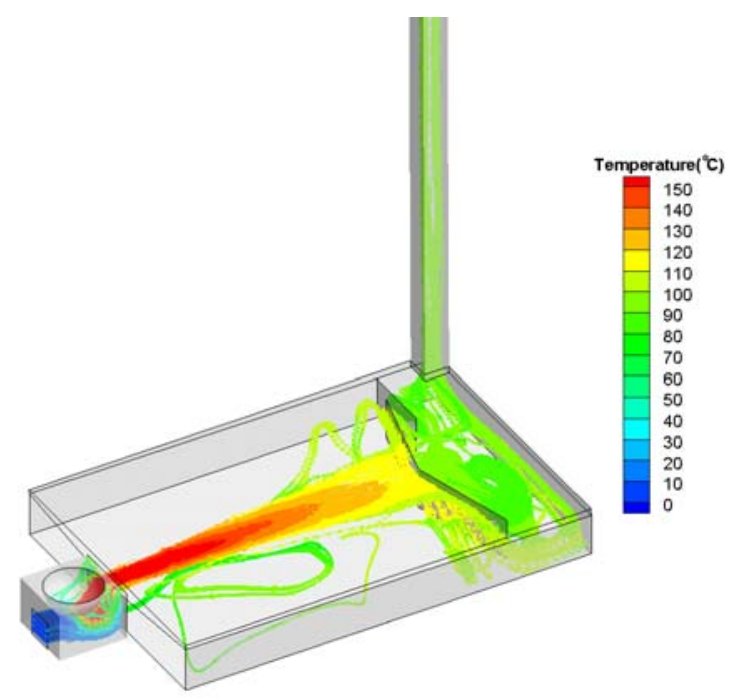

(D)

Figure 6. Streamline of smoke flow inside kang flue originated from the stove gate . (A) Case 1 [Grid-flue grounded kang]. (B) Case 2 [Elevated kang]. (C) Case 3 [Elevated kang with aluminum layer]. (D) Case 4 [Elevated kang with a different plate thickness]. 


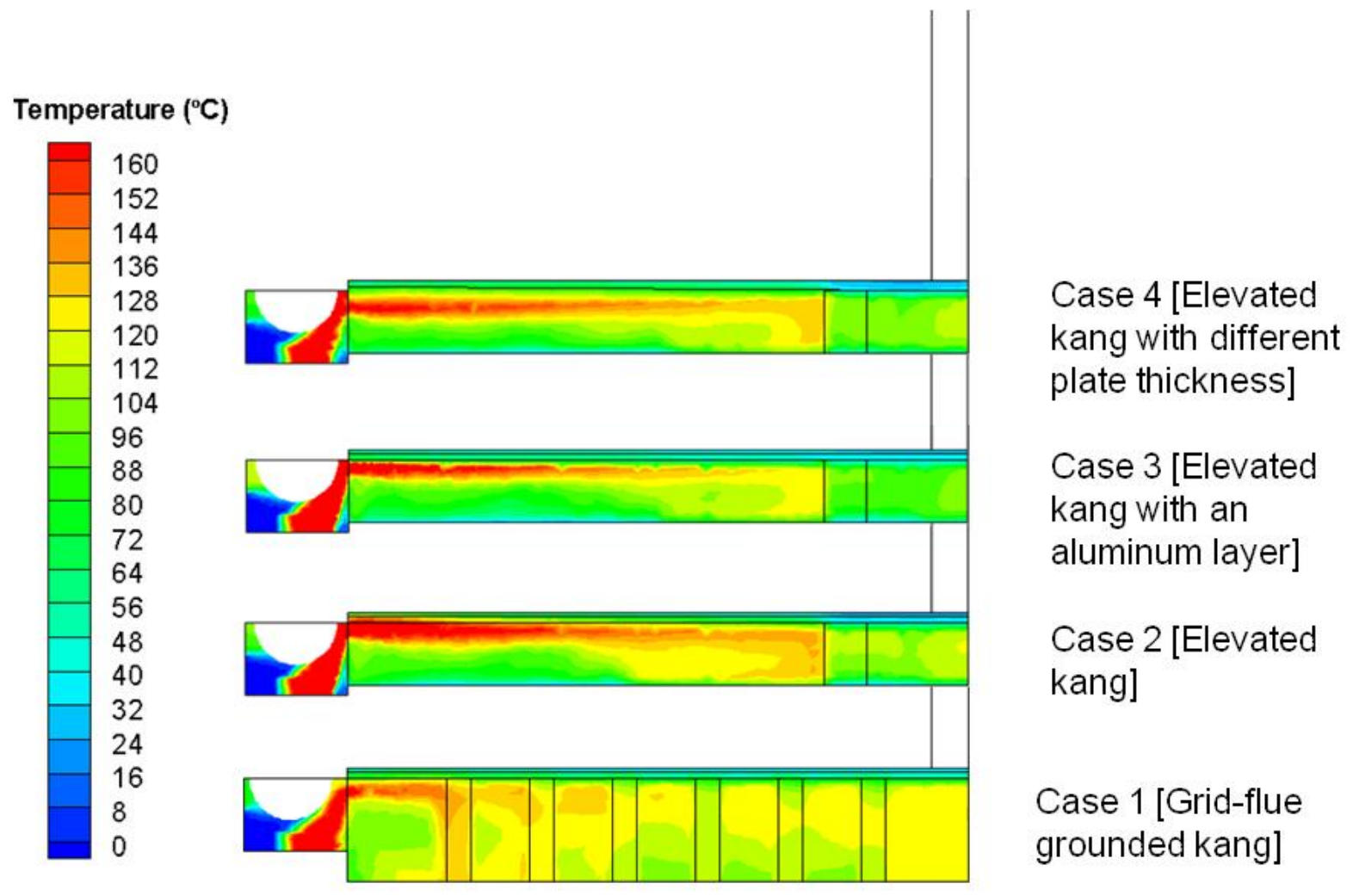

Figure 7. Smoke temperature contour at the middle plane of the kang flue. 


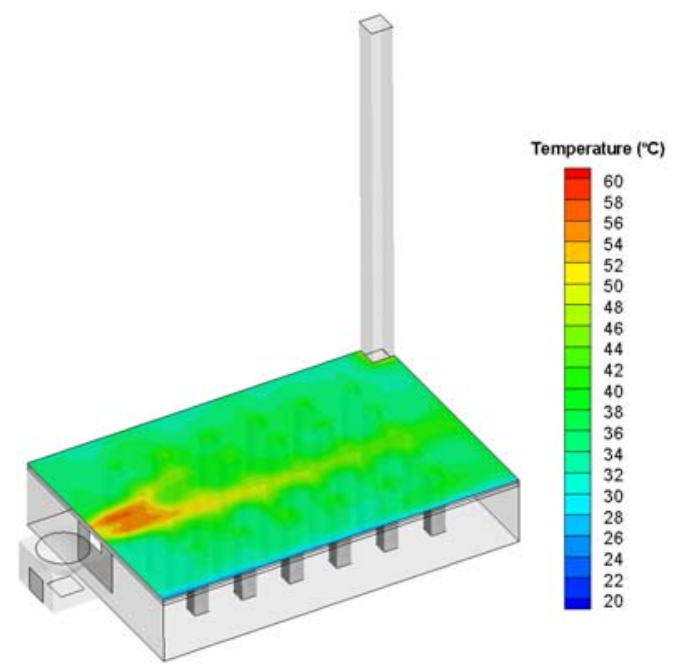

(A)

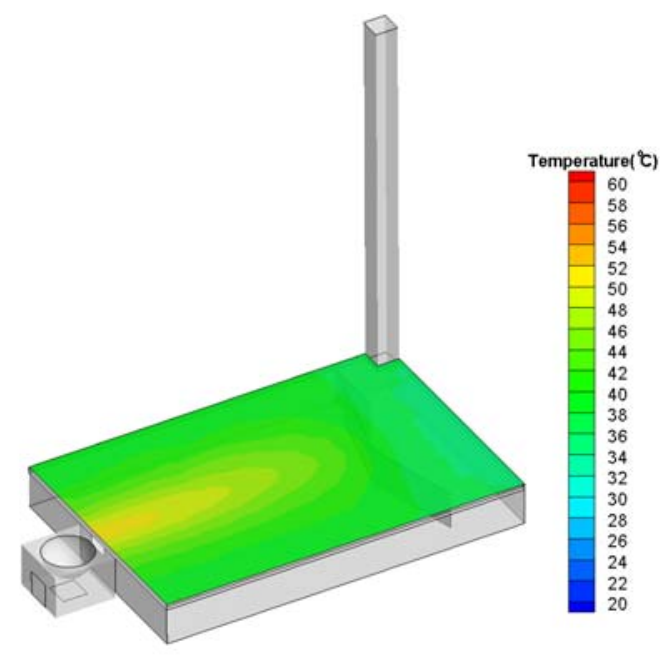

(C)

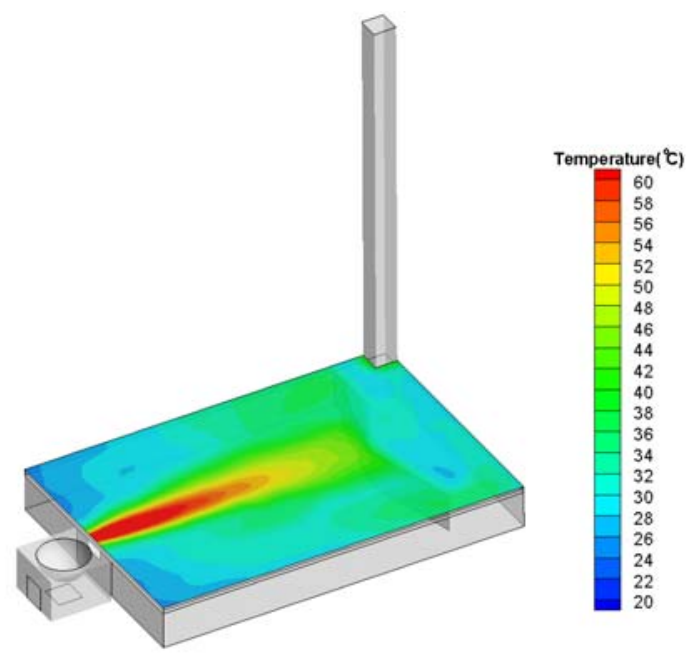

(B)

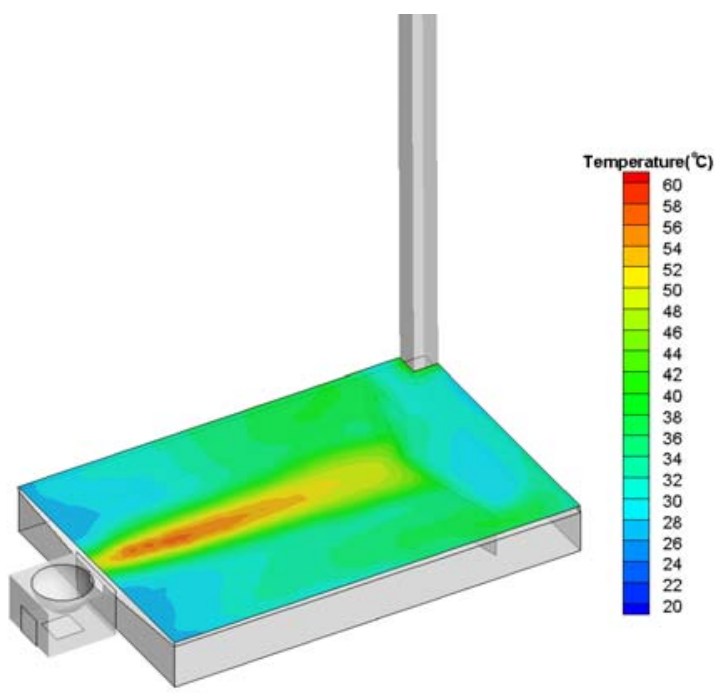

(D)

Figure 8. Temperature contours faceplate of kang for different test cases. (A) Case 1 [Grid-flue grounded kang]. (B) Case 2 [Elevated kang]. (C) Case 3 [Elevated kang with aluminum layer]. (D) Case 4 [Elevated kang with a different plate thickness]. 


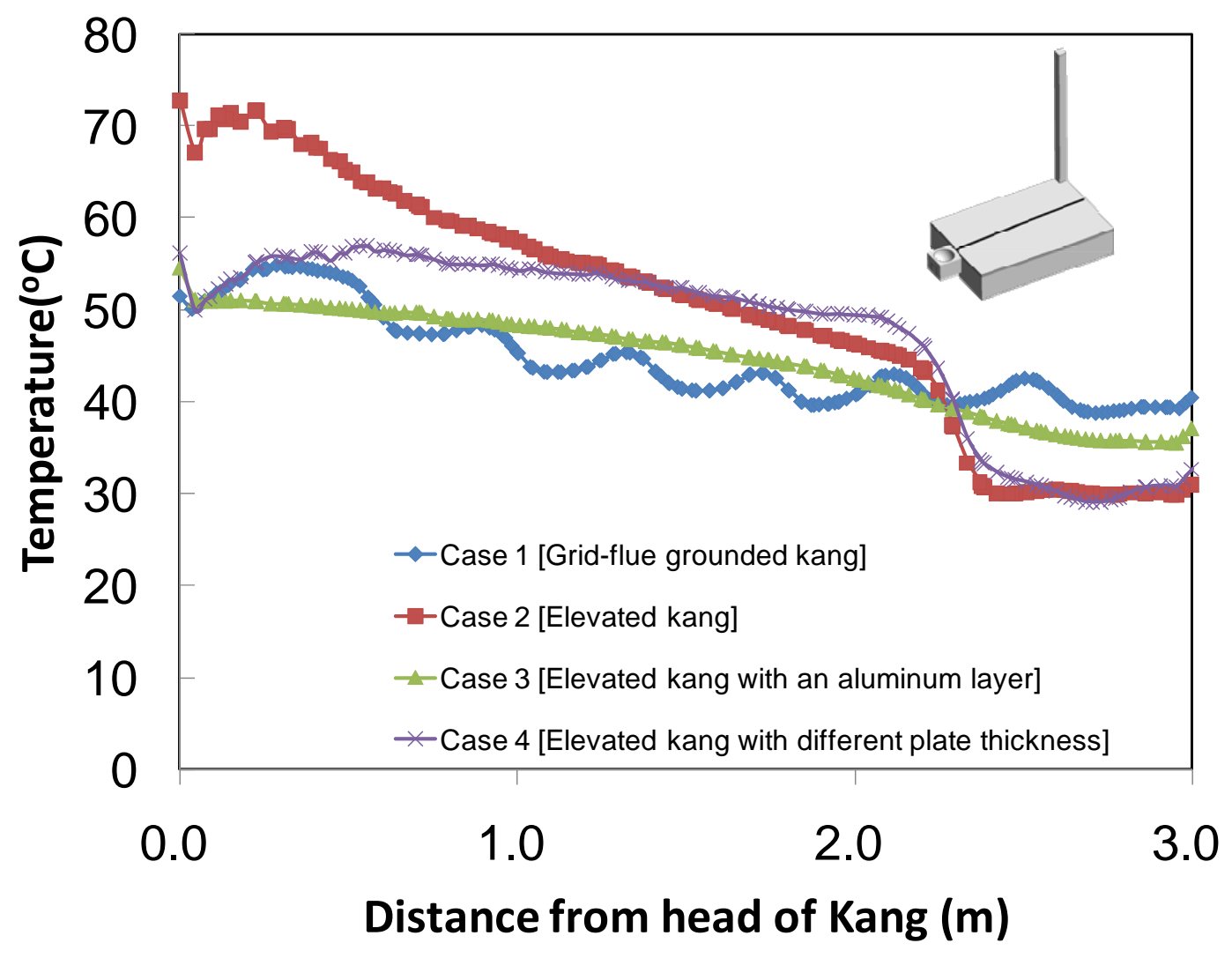

Figure 9. Temperature profiles along the middle line of kang faceplate . The position of the middle line is shown in the figure. 


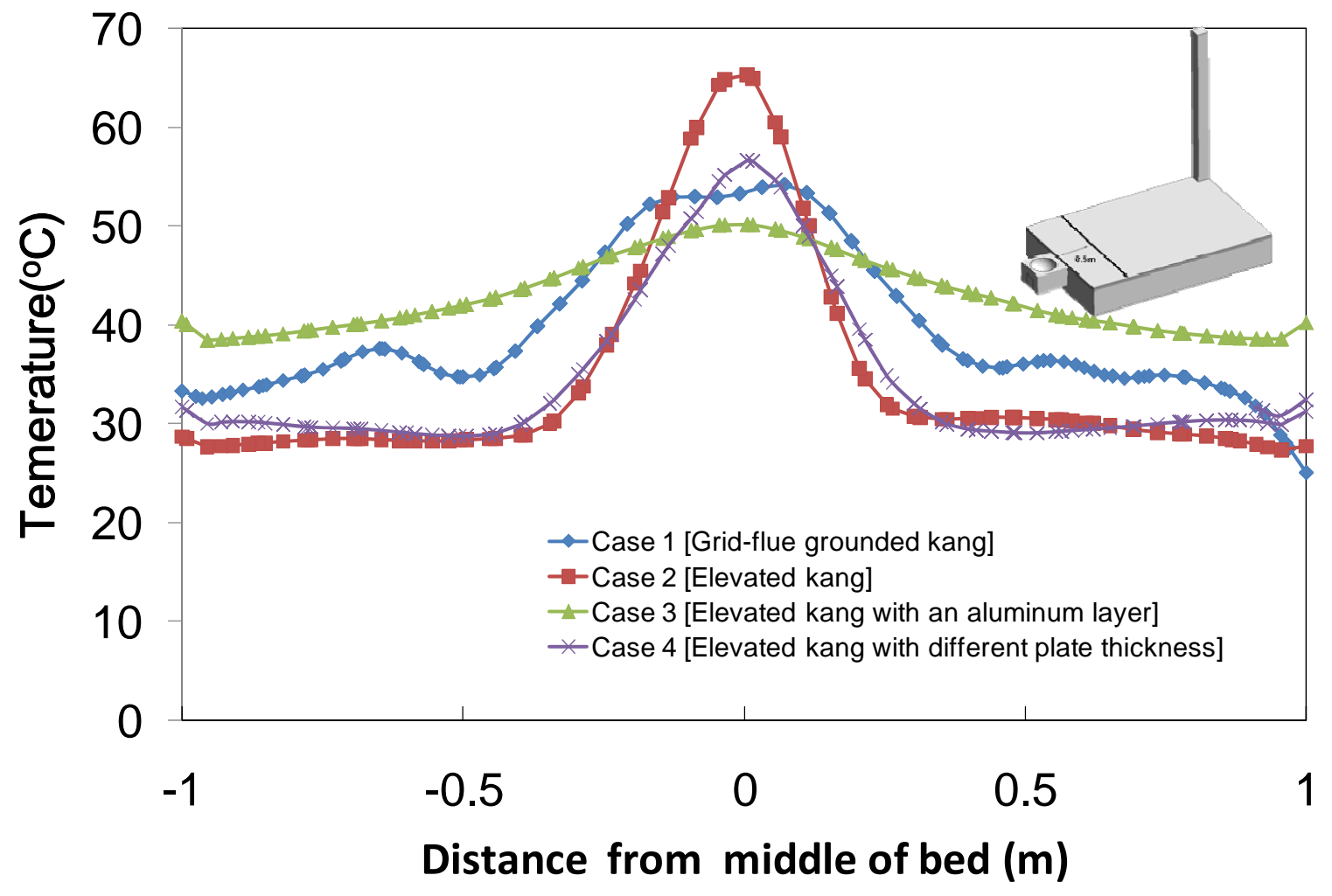

Figure 10. Temperature profiles along a horizontal line of the faceplate which is $0.5 \mathrm{~m}$ away from the kang head for different cases. The position of the line is shown in the figure. 


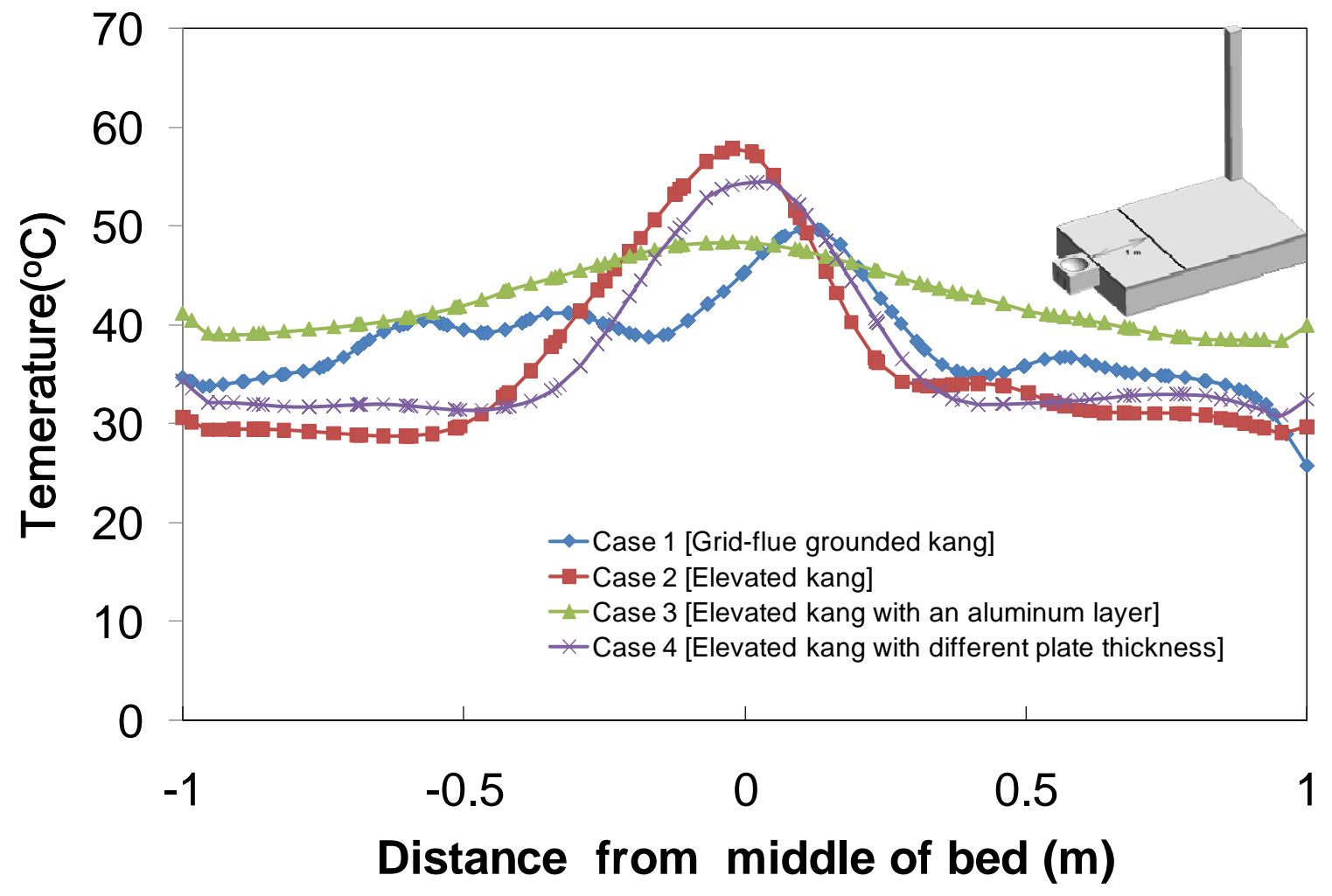

Figure 11. Temperature profiles along a horizontal line of the faceplate which is $1 \mathrm{~m}$ away from the head kang for different cases. The position of the line is shown in the figure. 


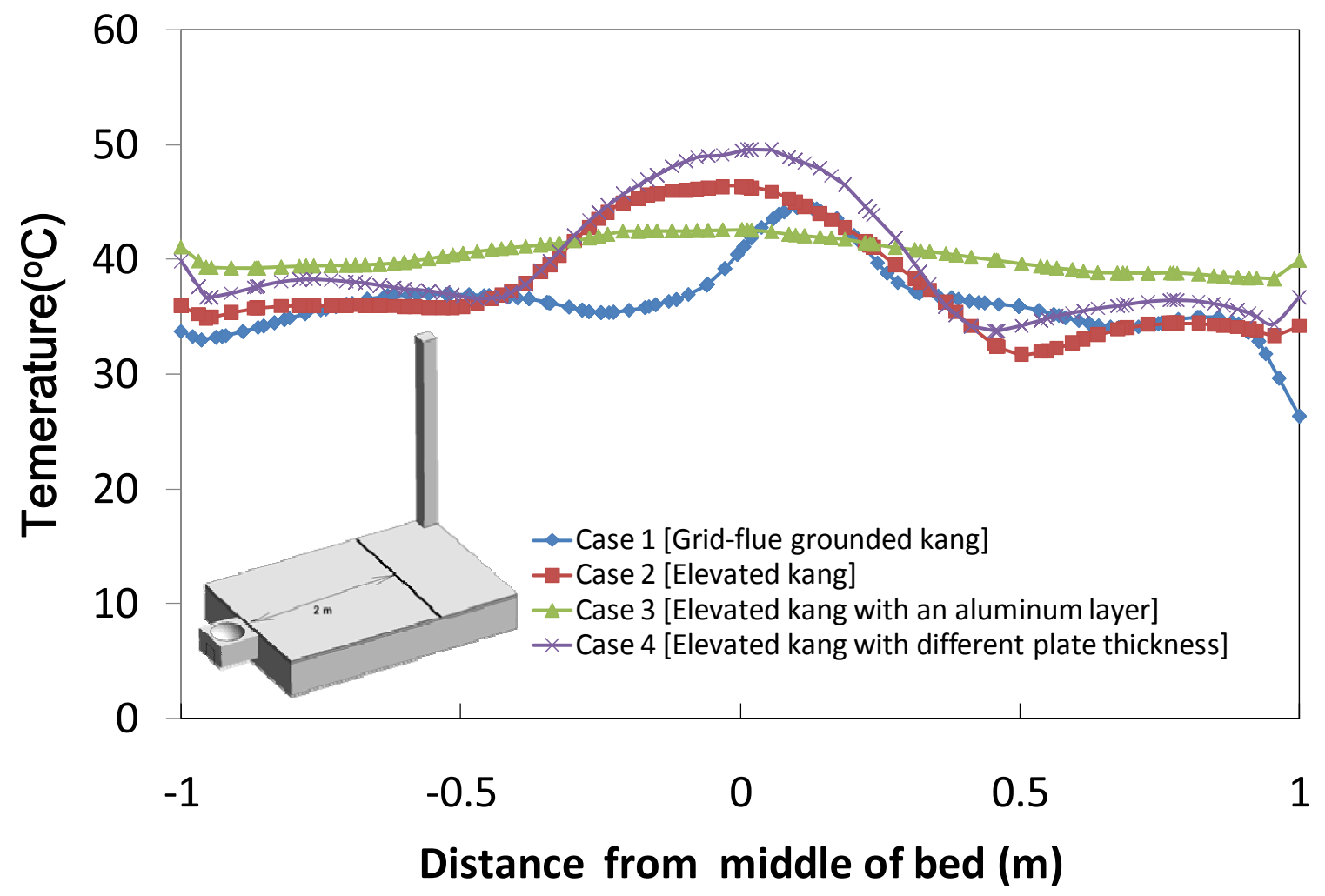

Figure 12. Temperature profiles along a horizontal line of faceplate which is $2 \mathrm{~m}$ distant from the head of kang for different cases. The position of the line was shown in the figure. 